\title{
Endoscopic resection as an independent predictive factor of local control in patients with T1bN0M0 esophageal squamous cell carcinoma treated with chemoradiotherapy: a retrospective study
}

Tomohiko Miyazaki ${ }^{1}$, Miyako Myojin ${ }^{* *} \mathbb{0}$, Masao Hosokawa², Hidefumi Aoyama ${ }^{3}$ Satoshi Okahara ${ }^{4}$ and Hiroaki Takahashi ${ }^{4}$

\begin{abstract}
Background: Although chemoradiotherapy (CRT) is one of the curative treatments for thoracic esophageal squamous cell carcinoma (ESCC) with submucosal invasion, the risk of local recurrence after CRT remains a clinical problem. This retrospective study aimed to analyze the predictive factors for local recurrence after CRT.

Methods: Ninety-one patients with clinical or pathological (c/p) T1 bNOMO thoracic ESCC who underwent CRT from 2004 to 2017 in our institution were analyzed retrospectively. Sixty-three patients were diagnosed with pathological $\mathrm{T} 1 \mathrm{~b}$ after undergoing initial endoscopic resection (ER) and treated with additional CRT; meanwhile, 28 patients were clinically diagnosed with T1b and underwent definitive CRT. We investigated the predictors of disease-specific survival (DSS) and local recurrence-free survival (LRFS) by performing univariate and multivariate analyses.

Results: The median observation period was 59.8 months. The 5-year DSS and LRFS rates were $84.3 \%$ (95\% confidence interval [Cl]: 76.1-92.5) and 87.1\% (95\% Cl: 79.1-95.1), respectively. The multivariate analysis revealed no significant predictors associated with DSS. On the contrary, ER (hazard ratio [HR]: $0.11,95 \%$ Cl: $0.02-0.48, p=0.003$ ) and tumor length (HR: $6.78,95 \% \mathrm{Cl}: 1.28-36.05, p=0.025)$ were recognized as independent predictive factors for LRFS. During follow-up, recurrence was observed in 18 patients (19.8\%). With regard to the patterns of relapse, local recurrence was the most common in 11 patients, and salvage ER was performed in 9 of 11 patients.
\end{abstract}

Conclusions: ER and tumor length were independent predictive factors for LRFS. Our study suggested that performance of ER prior to CRT improved the local control in patients with c/p T1 bNOMO ESCC. In addition, most of the patients who experienced local recurrence were treated with salvage $E R$, which contributed to preserving the organs.

Keywords: Esophageal squamous cell carcinoma, Chemoradiotherapy, Local recurrence, Endoscopic resection, Salvage therapy

*Correspondence: miyako98kazm@gmail.com

1 Department of Radiation Oncology, Keiyukai Sapporo Hospital, 1-1 Kita, Hondori-14, Shiroishi-ku, Sapporo 003-0027, Japan

Full list of author information is available at the end of the article

\section{Introduction}

Early stage esophageal squamous cell carcinoma (ESCC) with a depth of cT1a (7th UICC-TMN classification) is usually treated with endoscopic resection (ER). On the contrary, cT1b ESCC with submucosal (SM) invasion original author(s) and the source, provide a link to the Creative Commons licence, and indicate if changes were made. The images or other third party material in this article are included in the article's Creative Commons licence, unless indicated otherwise in a credit line to the material. If material is not included in the article's Creative Commons licence and your intended use is not permitted by statutory regulation or exceeds the permitted use, you will need to obtain permission directly from the copyright holder. To view a copy of this licence, visit http://creativecommons.org/licenses/by/4.0/. The Creative Commons Public Domain Dedication waiver (http://creativeco mmons.org/publicdomain/zero/1.0/) applies to the data made available in this article, unless otherwise stated in a credit line to the data. 
is treated with esophagectomy or chemoradiotherapy (CRT) due to the increased risk of lymph node metastasis $[1,2]$.

A phase II trial (JCOG9708) evaluating the efficacy of definitive CRT (dCRT) for stage I ESCC showed a good long-term outcome with a 4-year overall survival (OS) rate of $80.5 \%$ [3]. Following the results of JCOG9708, a randomized controlled trial (JCOG0502) was performed to confirm the non-inferiority of CRT to esophagectomy. Although the randomized part of the trial was not evaluated due to the shortage of cases, in the non-randomized part, the 5 -year OS rates were $86.5 \%$ for surgery and $85.5 \%$ for dCRT (adjusted hazard ratio [HR]: 1.05); this finding further demonstrated the efficacy of CRT [4]. In the JCOG 9708 study, although $87.5 \%$ of patients achieved complete remission, the 4-year recurrence-free survival rate was $52.8 \%$. According to existing studies, overall recurrence rate after radiotherapy (RT) or CRT for stage I ESCC was $20-40 \%$, while the intraesophageal recurrence rate was $10-30 \%$ [5-9].

ER or esophagectomy can be considered as salvage treatment for local recurrence after CRT, both of which can achieve curative outcomes. Although the impact of salvage treatment for local recurrence on OS is limited, improvement in local control is one of the important issues in CRT from the viewpoint of organ preservation $[10,11]$. This retrospective study analyzed the predictive factors related to the long-term prognosis and local control of clinical or pathological (c/p) T1bN0M0 ESCC treated with CRT.

\section{Methods}

\section{Patients}

According to the guidelines for esophageal cancer, patients with cT1a who are diagnosed as pT1b after ER are recommended to be treated according to treatment flow for cT1b, and both the patients with cT1b and pT1b are treated with esophagectomy or CRT. Since the main purpose of this study was to analyze prognostic factors of local recurrence after CRT for ESCC, we included the patients with c/p T1b who were eligible for CRT. In this study, we retrospectively reviewed the medical charts of 91 patients with c/p T1bNOM0 ESCC treated with CRT in our institution from 2004 to 2017, selected according to the following inclusion criteria: (1) aged less than 83 years, which was the age limit of patients eligible for CRT in our institution; (2) with histologically proved squamous cell carcinoma; (3) whose primary tumor site was the thoracic esophagus; (4) whose depth of tumor invasion was diagnosed as c/p T1b; (5) with no clinical evidence of lymph node or distant metastasis; and (6) with no history of chemotherapy and/or RT for esophageal carcinoma.
The evaluation of depth of tumor invasion was based on the Japanese Classification of Esophageal Cancer, 11th edition [12] using esophagogastroduodenoscopy (EGD) and endoscopic ultrasound (EUS) by gastroenterologists. cT1b-SM1 indicates tumor invasion into the upper third of the SM layer, while cT1b-SM2 indicates tumor invasion into the middle third of the SM layer. For cT1a or cT1b-SM1, ER was performed as the initial curative treatment. Patients with pT1b after ER underwent additional CRT to prevent lymph node metastasis. For patients with cT1b-SM2, ER was preceded by diagnostic treatment for tumors that a gastroenterologist determined to be completely resectable, while the rest of the patients were treated with CRT without ER.

\section{Chemoradiotherapy}

RT planning was performed by obtaining three-dimensional computerized axial tomography (CAT) images and using radiation treatment planning systems: Pinnacle versions 8.0-9.10 (Philips, Eindhoven, The Netherlands). The gross tumor volume (GTV) was contoured on the planning CAT images using all available resources. Where necessary, the tumor position was marked endoscopically with clips to determine the GTV. The primary clinical target volume (CTV-P) was identified by adding 2-3 cm margins in the cranio-caudal direction and $0.5 \mathrm{~cm}$ margins in the lateral direction from the GTV. In the elective nodal irradiation (ENI) case, the CTV included both CTV-P and all prophylactic regional lymph node areas. In the involved field irradiation (IFI) cases, the CTV was defined as the region including the CTV-P and an optional part of the regional lymph node area. If the GTV was not present after the ER, CTV was considered as equivalent to the prophylactic regional lymph node area. The planning target volume was identified by adding a $1-1.5 \mathrm{~cm}$ margins from the CTV.

A different technique was used to perform ENI during the periods of RT. From December 2004 to March 2009, the planned doses of 39.6-65 Gy in 20-26 fractions were delivered to the isocenter with opposed/unopposed portals using the cord-sparing technique. From April 2009 to 2017, a dose of 50.4 Gy in 28 fractions was delivered with anterior/posterior opposed and additional oblique portals [13]. After completing the initial plan, in patients who required radical irradiation, a tumor boost of $9 \mathrm{~Gy}$ in 5 fractions was delivered with cord-sparing oblique portals to the primary tumor or tumor bed after ER.

The standard doses of drugs used for chemotherapy were as follows: $700 \mathrm{mg} / \mathrm{m}^{2}$ of 5 -fluorouracil (5-FU) from day 1 to day 5 and $70 \mathrm{mg} / \mathrm{m}^{2}$ cisplatin (CDDP) on day 1 . Two courses of 5-FU and CDDP were administered during RT at intervals of at least 3 weeks, depending on the hematological data or the patient's general condition. In 
one patient with renal dysfunction, nedaplatin was used instead of CDDP.

\section{Follow-up}

After CRT was completed, all patients were included in the follow-up program. The follow-up started on the first day of CRT and ended on the date of death, date of the patient's last visit to our hospital, or date that the patient was last known to be alive as confirmed by a telephone interview or a letter from the patient's referring physician. The EGD and CAT scans were performed every 4-6 months for the first 5 years. When suspected tumor was found by EGD, esophageal biopsies were carried out. Lymph node or distant metastasis was examined by performing a CAT scan or a positron emission tomography/computed tomography scan. Lymph node metastasis was assessed according to the Japanese Classification of Esophageal Cancer, 11th edition [12]. For patients who developed recurrence, salvage treatments were considered, including ER, surgery, chemotherapy, RT, CRT, and other palliative treatments. We calculated the OS rate, disease-specific survival (DSS) rate, and local recurrence-free survival (LRFS) rate from the start date of CRT to the date of the last follow-up. LRFS was defined as recurrence within the esophageal cavity and did not include regional lymph node recurrence and distant metastasis. Toxicities were assessed according to the National Cancer Institute Common Terminology Criteria for Adverse Events version 4.0.

\section{Statistical methods}

The Kaplan-Meier method was used for calculating the survival rates, and the difference in survival curves was compared by the log-rank test. The categorical variables were compared using chi-square test and Fisher's exact test. For all analyses, a two-sided $p$ value of $<0.05$ was considered significant. To confirm the predictors of DSS and LRFS, a series of multivariate analyses were carried out using a Cox proportional hazards model. A multivariate analysis was performed for variables with a $p$ value less than 0.2 in the univariate analyses. All statistical analyses were conducted using the SPSS software (version 26; IBM SPSS Statistics, Chicago, IL, USA).

\section{Results}

\section{Patient and tumor characteristics}

The patient and tumor characteristics are summarized in Table 1. The median observation period was 59.8 (range, $0.7-190.7$ ) months, and the median age was 69 (range, 47-81) years. Of the 91 patients, 63 were treated with CRT after undergoing the initial ER (ER-CRT group). The remaining 28 patients were treated with dCRT without ER (dCRT group). Three patients failed to complete
Table 1 Patient and tumor characteristics in all patients

\begin{tabular}{|c|c|c|}
\hline Characteristic & Number & Percent \\
\hline Median age (years) & 69 & (Range 47-81) \\
\hline \multicolumn{3}{|l|}{ Gender } \\
\hline Male & 77 & 84.6 \\
\hline Female & 14 & 15.4 \\
\hline \multicolumn{3}{|l|}{ Performance status } \\
\hline 0 & 86 & 94.5 \\
\hline$\geq 1$ & 5 & 5.5 \\
\hline \multicolumn{3}{|c|}{ Observation period (month) } \\
\hline Median & 59.8 & (Range 0.7-190.7) \\
\hline \multicolumn{3}{|l|}{ Main tumor location } \\
\hline Upper thoracic & 10 & 11.0 \\
\hline Middle thoracic & 54 & 59.3 \\
\hline Lower thoracic & 27 & 29.7 \\
\hline \multicolumn{3}{|l|}{ Tumor length (cm) } \\
\hline Median & 2 & (Range 1-9) \\
\hline \multicolumn{3}{|c|}{ Circumference of tumor } \\
\hline$<3 / 4$ & 73 & 80.2 \\
\hline$\geq 3 / 4$ & 18 & 19.8 \\
\hline \multicolumn{3}{|l|}{ Multiple lesion } \\
\hline No & 77 & 84.6 \\
\hline Yes & 14 & 15.4 \\
\hline \multicolumn{3}{|l|}{ Endoscopic resection } \\
\hline No & 28 & 30.8 \\
\hline Yes & 63 & 69.2 \\
\hline \multicolumn{3}{|l|}{ RT field } \\
\hline$|F|$ & 13 & 14.3 \\
\hline ENI & 78 & 85.7 \\
\hline \multicolumn{3}{|l|}{ Radiation dose (Gy) } \\
\hline$<50 \mathrm{~Gy}$ & 23 & 25.6 \\
\hline$\geq 50 \mathrm{~Gy}$ & 68 & 74.4 \\
\hline
\end{tabular}

$R T$ radiotherapy, IFI involved field irradiation, ENI elective nodal irradiation

the treatment due to the occurrence of fever $(n=2)$ and pneumonitis $(\mathrm{n}=1)$.

Table 2 shows the characteristics and pathological results of 63 patients who underwent ER as the initial treatment. All patients underwent endoscopic submucosal dissection (ESD) with en bloc resection, except for one patient who underwent endoscopic mucosal resection (EMR). Fifty tumors (79.4\%) demonstrated pT1bSM2 invasion. Pathological findings included lymphatic invasion in 20 (31.7\%) patients, venous invasion in 14 (22.2\%) patients, and incomplete resection in 6 (9.5\%) patients.

\section{Outcomes}

The 5-year OS, 5-year DSS, and 5-year LRFS rates were 73.7\% (95\% CI: 64.1-83.3), 84.3\% (95\% CI: 76.1-92.5), 
Table 2 Results of endoscopic resection

\begin{tabular}{|c|c|c|}
\hline Characteristic & Number & Percent \\
\hline \multicolumn{3}{|l|}{ Method of ER } \\
\hline EMR & 1 & 1.6 \\
\hline ESD & 62 & 98.4 \\
\hline \multicolumn{3}{|l|}{ Type of resection } \\
\hline En bloc & 62 & 98.4 \\
\hline Unknown & 1 & 1.6 \\
\hline \multicolumn{3}{|l|}{ Pathological tumor depth } \\
\hline SM1 & 13 & 20.6 \\
\hline SM2 & 50 & 79.4 \\
\hline \multicolumn{3}{|c|}{ Tumor differentiation grade } \\
\hline Unknown & 20 & 31.7 \\
\hline G1 & 3 & 4.8 \\
\hline G2 & 34 & 54.0 \\
\hline G3 & 6 & 9.5 \\
\hline G4 & 0 & 0.0 \\
\hline \multicolumn{3}{|l|}{ Lymphatic invasion } \\
\hline Positive & 20 & 31.7 \\
\hline Negative & 38 & 60.3 \\
\hline Unknown & 5 & 7.9 \\
\hline \multicolumn{3}{|l|}{ Venous invasion } \\
\hline Positive & 14 & 22.2 \\
\hline Negative & 45 & 71.4 \\
\hline Unknown & 4 & 6.3 \\
\hline \multicolumn{3}{|l|}{ Horizontal margin } \\
\hline Positive & 6 & 9.5 \\
\hline Negative or uncertain & 57 & 90.5 \\
\hline \multicolumn{3}{|l|}{ Vertical margin } \\
\hline Positive & 1 & 1.6 \\
\hline Negative or uncertain & 62 & 98.4 \\
\hline
\end{tabular}

$E R$ endoscopic resection, EMR endoscopic mucosal resection, ESD endoscopic submucosal dissection

and $87.1 \%$ (95\% CI: 79.1-95.1), respectively. During follow-up, 18 patients developed recurrence (Table 3). The most common recurrence patterns were local recurrence in 11 patients (12.1\%), followed by regional lymph node metastasis in 6 patients $(6.6 \%)$, and lung metastasis (1.1\%) in 1 patient. As the salvage treatment for local recurrence, ESD was performed in 9 of the 11 patients. Two patients did not undergo salvage treatment due to the coexistence of multiple cancers, and received the best supportive care. Two patients with lymph node metastasis underwent esophagectomy, one patient with lung metastasis was treated with surgical partial lung resection, and the other patient received chemotherapy.

Table 4 shows the 5-year DSS and 5-year LRFS rates for each of the clinical factors as well as; the results of univariate analyses. For the 5 -year DSS, the performance status and ER were significant predictive factors $(p<0.05)$; however, the multivariate analysis revealed no significant factors (Table 5). Gender was excluded from the multivariate analysis because all female patients were alive during the observation period. By contrast, the multivariate analysis of the 5-year LRFS showed that tumor length and ER were independent predictive factors, with hazard ratios [HRs] of 6.78 (95\% CI: $1.28-36.05, p=0.025)$ for tumor length and 0.11 (95\% CI: $0.02-0.48, p=0.003$ ) for ER (Table 6). The 5-year LRFS rate was $93.2 \%$ (95\% CI: 85.6-100) in the ER-CRT group, which was significantly higher $(p<0.001)$ than $74.9 \%$ (95\% CI: $56.9-92.9)$ in the dCRT group (Fig. 1).

\section{Comparison of characteristics between the ER-CRT group and the dCRT group}

Table 7 summarizes the characteristics of the ER-CRT and the dCRT groups. In the dCRT group, a significant number of tumors exceeded $3 / 4$ of the esophageal circumference $(p=0.048)$. The reason for this is that the guidelines for ER recommend esophagectomy or CRT in patients with tumor that was occupying the entire circumference of the esophagus because of increasing risk of esophageal stricture. Moreover, the total radiation doses were significantly higher in the dCRT group $(p=0.001)$. It was because boost irradiation was required to complete the curative therapy in this group.

\section{Toxicities}

The adverse events (AEs) are summarized in Table 8 . Leukopenia was one of the most common acute AEs, and the incidence of grade 3 or higher leukopenia was 14.3\% in our study. Other grade 3 or higher acute AEs included esophagitis (3.3\%) and fever (1.1\%). Grade 3 or higher late AEs included pleural effusion (1.1\%) and pericardial effusion (1.1\%). Grade 3 or higher pneumonitis was found in $4.4 \%$ of patients, and they were all treated with corticosteroids. One patient died from grade 5 radiation pneumonitis (RP) in this study.

\section{Discussion}

In this retrospective study of c/p T1b ESCC, the multivariate analysis did not reveal any statistically significant predictors of DSS; in contrast, tumor length $(p=0.025)$ and ER $(p=0.003)$ were recognized as independent predictors of LRFS. A previous study reported tumor length as a predictor of local control. Ishikawa et al. analyzed patients treated with RT alone for stage I ESCC and reported that local recurrence tended to be more common in those with tumor larger than $5 \mathrm{~cm}$ [14]. We did not find any studies conducted in the CRT group that indicated tumor length as a risk factor for local recurrence. Most of the studies adopted a median value as the threshold of tumor length. Although it is difficult to set an absolute standard value because a median value of the 
Table 3 Summary of recurrence events after CRT

\begin{tabular}{|c|c|c|c|c|c|c|}
\hline Treatment & RT field & Dose (Gy) & Primary tumor site & Recurrence site & RFS (month) & Salvage treatment \\
\hline dCRT & ENI & 59.4 & $\mathrm{Lt}$ & Local & 7.1 & ESD \\
\hline dCRT & $\mathrm{IFI}$ & 60 & UtMtLt & Local & 7.2 & ESD \\
\hline $\mathrm{dCRT}$ & ENI & 59.4 & Mt & Local & 8.2 & ESD \\
\hline $\mathrm{dCRT}$ & ENI & 48.6 & Mt & Local & 18.9 & $\mathrm{BSC}$ \\
\hline$d C R T$ & $\mathrm{ENI}$ & 59.4 & Mt & LN (in field) & 26.6 & Chemotherapy \\
\hline dCRT & ENI & 59.4 & Ut & Local & 31.8 & $\mathrm{BSC}$ \\
\hline $\mathrm{dCRT}$ & $\mathrm{ENI}$ & 59.4 & MtLt & Local & 47.5 & ESD \\
\hline $\mathrm{dCRT}$ & $\mid \mathrm{FI}$ & 65 & Mt & LN (in field), Pleura & 58.8 & Chemotherapy \\
\hline $\mathrm{dCRT}$ & $\mathrm{ENI}$ & 59.4 & LtMt & Local & 63.7 & ESD \\
\hline $\mathrm{dCRT}$ & $\mathrm{ENI}$ & 59.4 & $\mathrm{Lt}$ & Local & 76.7 & ESD \\
\hline ER-CRT & $\mathrm{ENI}$ & 40 & Mt & Lung & 1.4 & Local resection of lung \\
\hline ER-CRT & $\mathrm{ENI}$ & 39.6 & Mt & LN (out of field) & 13.1 & Chemotherapy \\
\hline ER-CRT & $\mathrm{ENI}$ & 28 & $\mathrm{Lt}$ & LN (in field) & 15.3 & Surgery \\
\hline ER-CRT & $\mathrm{ENI}$ & 40 & Mt & LN (in field) & 22.5 & Surgery \\
\hline ER-CRT & $\mathrm{ENI}$ & 50.4 & Mt & Local & 29.3 & ESD \\
\hline ER-CRT & $\mathrm{ENI}$ & 50.4 & Mt & LN (in field) & 31.0 & Chemotherapy \\
\hline ER-CRT & $\mathrm{ENI}$ & 39.6 & $\mathrm{Lt}$ & Local & 43.2 & ESD \\
\hline ER-CRT & ENI & 50.4 & Mt & Local & 52.2 & ESD \\
\hline
\end{tabular}

$C R T$ chemoradiotherapy, $R T$ radiotherapy, RFS recurrence-free survival, $d C R T$ definitive CRT, ENI elective nodal irradiation, ESD endoscopic submucosal dissection, IFI involved field irradiation, $L N$ lymph node, BSC best supportive care, ER-CRT combined endoscopic resection and CRT

tumor length varies among studies, more careful followup is needed for the tumor of larger size.

Meanwhile, several studies have shown that a combination of ER and CRT can improve local control. Yoshimizu et al. compared the long-term results of the ER-CRT group and the dCRT group. Although no significant difference was observed in the 5-year OS between the two groups, the ER-CRT group showed significantly higher local control rate $(p<0.05)$ [15]. Kawaguchi et al. reported that $19.4 \%$ of patients in the dCRT group had local recurrence, while none of the patients in the ERCRT group had local recurrence [16]. Hamada et al. also reported that local recurrence occurred in 3\% (2/66) of the patients in the ER-CRT group, which was lower than that in the conventional dCRT group [17]. In our study, we confirmed that ER is a significant predictor of local control using the multivariate analysis. This result reinforces the validity of existing reports. With regard to the efficacy of combined ER and CRT treatment for stage I ESCC, Minashi et al. conducted a prospective study (JCOG0508) and reported a 3-year OS rate of $90.7 \%$ in the ER-CRT group [18]. In the study, cT1b-SM2 tumor, which was not an indication for ER according to the previous guidelines, was included, and therapeutic diagnostic ER was performed in $35.6 \%$ of the patients with cT1b-SM2 tumor. The results of the JCOG0508 study suggested that the combination of ER and CRT can be considered as a useful treatment even for cT1b-SM2 tumor, for which complete resection by ESD is expected. In our study, $79.4 \%$ of the patients who underwent ER had pT1b-SM2 tumor and showed favorable long-term results. In addition, as we confirmed in this study, ER is a predictor of improved local control, which may reduce the number of patients requiring salvage surgery due to local recurrence. A combination of ER and CRT treatment allows organ preservation for stage I ESCC and is considered a promising treatment strategy.

In 2003, Hattori et al. reported the results of the first EMR performed as a salvage treatment for local recurrence after CRT in Japan [19]. Consequently, several studies have been conducted to examine the effectiveness and safety of salvage ER after CRT [20-22], it has been regarded as important to detect recurrence after CRT while tumor remains in the superficial layer. In our institution, patients treated with CRT underwent followup EGD and CAT scans every 4-6 months during the first 5 years after CRT. In this study, local recurrence was observed in 11 patients during follow-up, and salvage ER was performed in 9 of the 11 patients. This result suggests that patients treated with CRT should be monitored for any signs of local recurrence, and efforts should be made for the early detection of local recurrence by performing endoscopic observations at an appropriate frequency.

Grade 3 or higher pneumonitis was found in $4.4 \%$ of patients. This value is slightly higher than that reported in previous studies $(1-3 \%)[4,8,18]$. We have previously 
Table 4 Univariate analyses for disease-specific survival and local recurrence-free survival rates

\begin{tabular}{|c|c|c|c|c|c|}
\hline Variables & Number & 5-year DSS (\%) & $p$ value & 5-year LRFS (\%) & $p$ value \\
\hline \multicolumn{6}{|l|}{ Age, years } \\
\hline$<70$ & 43 & 92.9 & 0.059 & 91.8 & 0.140 \\
\hline$\geq 70$ & 48 & 74.5 & & 82.8 & \\
\hline \multicolumn{6}{|l|}{ Gender } \\
\hline Male & 77 & 81.3 & 0.094 & 89.3 & 0.899 \\
\hline Female & 14 & 100.0 & & 78.8 & \\
\hline \multicolumn{6}{|l|}{ Performance status } \\
\hline 0 & 86 & 87.3 & $0.001^{*}$ & 87.0 & 0.498 \\
\hline$\geq 1$ & 5 & 40.0 & & 100.0 & \\
\hline \multicolumn{6}{|l|}{ Tumor location } \\
\hline Upper thoracic & 10 & 75.0 & 0.829 & 77.1 & 0.567 \\
\hline Middle thoracic & 54 & 85.5 & & 90.9 & \\
\hline Lower thoracic & 27 & 87.4 & & 90.9 & \\
\hline \multicolumn{6}{|l|}{ Tumor length } \\
\hline$<3 \mathrm{~cm}$ & 46 & 91.9 & 0.111 & 97.4 & $0.012^{*}$ \\
\hline$\geq 3 \mathrm{~cm}$ & 45 & 76.3 & & 76.7 & \\
\hline \multicolumn{6}{|c|}{ Circumference of tumor } \\
\hline$<3 / 4$ & 73 & 85.5 & 0.681 & 89.6 & 0.131 \\
\hline$\geq 3 / 4$ & 18 & 80.1 & & 79.1 & \\
\hline \multicolumn{6}{|l|}{ Multiple lesion } \\
\hline No & 77 & 85.2 & 0.757 & 87.2 & 0.824 \\
\hline Yes & 14 & 79.6 & & 92.3 & \\
\hline \multicolumn{6}{|c|}{ Endoscopic resection } \\
\hline No & 28 & 72.1 & $0.045^{*}$ & 74.7 & $<0.001^{*}$ \\
\hline Yes & 63 & 89.2 & & 93.2 & \\
\hline \multicolumn{6}{|l|}{ RT field } \\
\hline$|F|$ & 13 & 66.7 & 0.058 & 92.3 & 0.649 \\
\hline ENI & 78 & 86.9 & & 87.1 & \\
\hline \multicolumn{6}{|l|}{ Radiation dose } \\
\hline$<50 \mathrm{~Gy}$ & 23 & 81.5 & 0.857 & 89.1 & 0.400 \\
\hline$\geq 50 \mathrm{~Gy}$ & 68 & 85.2 & & 86.3 & \\
\hline
\end{tabular}

DSS disease-specific survival, LRFS local recurrence-free survival, $R T$ radiotherapy, IFl involved field irradiation, ENI elective nodal irradiation ${ }^{*} p<0.05$

reported the relationship between respiratory toxicities and the percentage volume of the whole lung receiving at least 5-40 Gy (V5-V40) in patients with thoracic ESCC treated with ENI [13]. In the study, V5 and V10 in all lungs were significantly higher in the group with grade 2 or higher RP. V5 $(<55 \%)$, V10 $(<37 \%)$ and V20 ( $<25 \%)$ were used as dose constraints; ENI therapy was safely implemented by reducing the risk of adverse events. There was no significant difference in grade 3 or higher AEs between the ER-CRT group and the dCRT group. Esophageal stricture is known to be a problem as a late AEs after ER. In this study, out of 63 patients who underwent ER, grade 2 esophageal stricture was found in 6 patients $(9.5 \%)$, but no grade 3 or higher was found.
Minashi et al. also reported that grade 3 esophageal stricture was observed in one patient (0.6\%) after ER, however no other severe AEs were observed and the safety of ER-CRT was acceptable [18].

In 2016, we reported that PS was an independent prognostic factor for DSS and disease-free survival for patients with T1N0M0 ESCC [23]. In the study, cT1a tumors were also included and $33.8 \%$ of the patients were treated with RT alone. Since CRT is recommended in the Japanese guidelines [1], we thought it necessary to limit the analysis to patients treated with CRT. In the present study, we retrospectively analyzed the factors associated with local recurrence after CRT for ESCC, and included both the patients with pT1b who underwent ER and the 
Table 5 Multivariate analysis for disease-specific survival rate

\begin{tabular}{lll}
\hline Variables & HR $(\mathbf{9 5} \% \mathbf{C l})$ & $\boldsymbol{p}$ value \\
\hline $\begin{array}{l}\text { Age, years } \\
\quad<70\end{array}$ & 1.0 & \\
$\quad \geq 70$ & $2.42(0.67-8.82)$ & \\
Performance status & & \\
$\quad 0$ & 1.0 & 0.179 \\
$\quad \geq 1$ & $3.06(0.69-13.58)$ & \\
$\begin{array}{l}\text { Tumor length } \\
\quad<3 \text { cm }\end{array}$ & 1.0 & \\
$\quad \geq 3$ cm & $1.78(0.50-6.36)$ & 0.337 \\
Endoscopic resection & & \\
$\quad$ No & 1.0 & 0.509 \\
$\quad$ Yes & $0.65(0.18-2.32)$ & \\
RT field & & 0.125 \\
$\quad$ IFI & 1.0 & \\
ENI & $0.37(0.10-1.32)$ & \\
\hline
\end{tabular}

$H R$ hazard ratio, $\mathrm{Cl}$ confidence interval, $R T$ radiotherapy, IFI involved field irradiation, ENI elective nodal irradiation

Table 6 Multivariate analysis for local recurrence-free survival rate

\begin{tabular}{lll}
\hline Variables & HR $(\mathbf{9 5} \% \mathbf{C l})$ & $\boldsymbol{p}$ value \\
\hline $\begin{array}{l}\text { Age, years } \\
\quad<70\end{array}$ & 1.0 & 0.456 \\
$\quad \geq 70$ & $1.70(0.42-6.85)$ & \\
$\begin{array}{l}\text { Tumor length } \\
\quad<3 \mathrm{~cm}\end{array}$ & $0.025^{*}$ \\
$\quad \geq 3 \mathrm{~cm}$ & 1.0 & \\
$\begin{array}{l}\text { Circumference of tumor } \\
\quad<3 / 4\end{array}$ & $6.78(1.28-36.05)$ & 0.441 \\
$\quad \geq 3 / 4$ & 1.0 & \\
Endoscopic resection & $0.57(0.13-2.40)$ & $0.003^{*}$ \\
$\quad$ No & 1.0 & \\
$\quad$ Yes & $0.11(0.02-0.48)$ &
\end{tabular}

$H R$ hazard ratio, $\mathrm{Cl}$ confidence interval ${ }^{*} p<0.05$

patients with cT1b who did not undergo ER. The multivariate analysis showed that ER was one of the predictors of local recurrence, and the diagnostic accuracy of cT1b in the dCRT group was a problem in interpreting the results. A clinical depth of tumor invasion was diagnosed by EUS along with the findings of magnifying endoscopy. According to the meta-analysis on EUS, the sensitivity and specificity of cT1b diagnosis of superficial esophageal cancer by EUS were both $86 \%$ (diagnostic accuracy: $86 \%$ ), and the area under the curve calculated from the summary receiver operating characteristic curve was

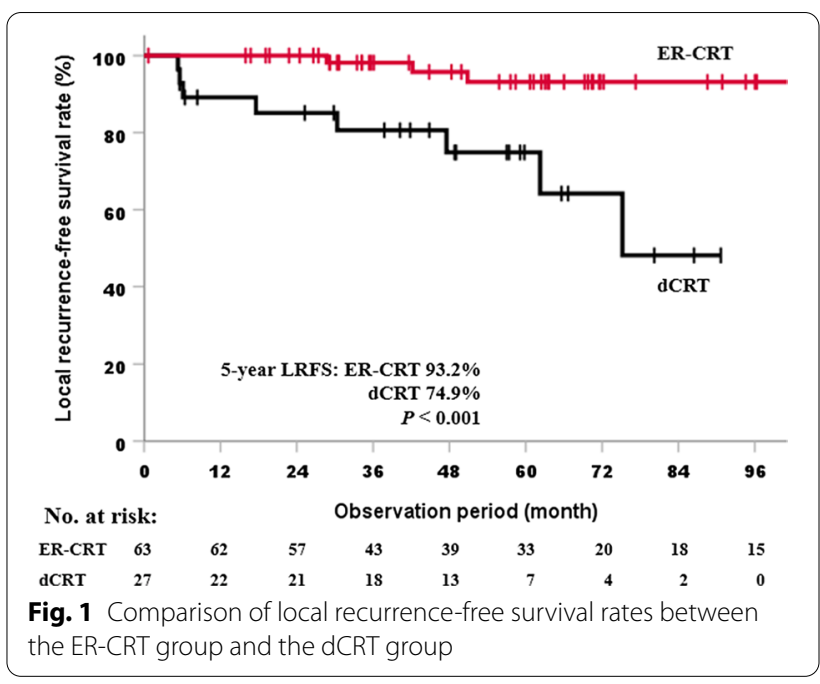

Table 7 Characteristics of the ER-CRT and the dCRT groups

\begin{tabular}{|c|c|c|c|}
\hline Characteristic & $\begin{array}{l}\text { ER-CRT } \\
(n=63)\end{array}$ & $\mathrm{dCRT}(\mathrm{n}=28)$ & $p$ value \\
\hline \multicolumn{4}{|l|}{ Age, years } \\
\hline$<70$ & 35 & 13 & \multirow[t]{2}{*}{0.421} \\
\hline$\geq 70$ & 28 & 15 & \\
\hline \multicolumn{4}{|c|}{ Performance status } \\
\hline 0 & 60 & 26 & \multirow[t]{2}{*}{0.641} \\
\hline$\geq 1$ & 3 & 2 & \\
\hline \multicolumn{4}{|l|}{ Tumor length } \\
\hline$<3 \mathrm{~cm}$ & 34 & 12 & \multirow[t]{2}{*}{0.328} \\
\hline$\geq 3 \mathrm{~cm}$ & 29 & 16 & \\
\hline \multicolumn{4}{|c|}{ Circumference of tumor } \\
\hline$<3 / 4$ & 54 & 19 & \multirow[t]{2}{*}{$0.048^{*}$} \\
\hline$\geq 3 / 4$ & 9 & 9 & \\
\hline \multicolumn{4}{|l|}{ Multiple lesion } \\
\hline No & 56 & 21 & \multirow[t]{2}{*}{0.09} \\
\hline Yes & 7 & 7 & \\
\hline \multicolumn{4}{|l|}{ RT field } \\
\hline $\mathrm{IFI}$ & 7 & 6 & \multirow[t]{2}{*}{0.194} \\
\hline ENI & 56 & 22 & \\
\hline \multicolumn{4}{|l|}{ Radiation dose } \\
\hline$<50 \mathrm{~Gy}$ & 22 & 1 & \multirow[t]{2}{*}{$0.001^{*}$} \\
\hline$\geq 50 \mathrm{~Gy}$ & 41 & 27 & \\
\hline
\end{tabular}

$E R-C R T$ combined endoscopic resection and chemoradiotherapy, $d C R T$ definitive chemoradiotherapy, $R T$ radiotherapy, IFI involved field irradiation, ENI elective nodal irradiation

${ }^{*} p<0.05$

reported to be 0.93 [24]. At our institution, a diagnostic accuracy of cT1b ESCC by EUS is about $90 \%$. In addition, the Japanese guidelines recommends that EUS should be used to evaluate the clinical depth of tumor invasion. Based on the above, the possibility of cT1a and 
Table 8 Adverse events in all patients

\begin{tabular}{lcccc}
\hline & Grade 2 & Grade 3 & Grade 4 & Grade 5 \\
\hline $\begin{array}{lcccc}\text { Acute AEs } \\
\text { Leukopenia }\end{array}$ & $21(23.1)$ & $10(11.0)$ & $3(3.3)$ & $0(0.0)$ \\
$\quad$ Dermatitis & $5(5.5)$ & $0(0.0)$ & $0(0.0)$ & $0(0.0)$ \\
Esophagitis & $10(11.0)$ & $3(3.3)$ & $0(0.0)$ & $0(0.0)$ \\
Nausea & $4(4.4)$ & $0(0.0)$ & $0(0.0)$ & $0(0.0)$ \\
$\quad$ Pneumonitis & $0(0.0)$ & $1(1.1)$ & $0(0.0)$ & $0(0.0)$ \\
Fever & $3(3.3)$ & $1(1.1)$ & $0(0.0)$ & $0(0.0)$ \\
Late AEs & & & & \\
$\quad$ Esophageal stenosis & $6(6.6)$ & $0(0.0)$ & $0(0.0)$ & $0(0.0)$ \\
Pneumonitis & $1(1.1)$ & $1(1.1)$ & $1(1.1)$ & $1(1.1)$ \\
$\quad$ Pleural effusion & $1(1.1)$ & $1(1.1)$ & $0(0.0)$ & $0(0.0)$ \\
Pericardial effusion & $6(6.6)$ & $1(1.1)$ & $0(0.0)$ & $0(0.0)$ \\
\hline
\end{tabular}

AEs were evaluated according to the Common Terminology Criteria for Adverse Events version 4.0

AEs adverse events

cT2 tumors being mixed in the dCRT group was low, and we considered it was reasonable to include the patients with pT1b and cT1b in this study. However, this point was also the limitation of the present study. In the review of adjuvant therapy after ER, Tsou et al. mentioned that there were differences in clinical and pathological diagnosis between patients treated with or without ER, which should be kept in mind when interpreting the results [25]. Our study suggested the benefit of ER prior to CRT even in cT1b tumor, and we hope that our findings will help to conduct a prospective trial comparing the outcomes of ER-CRT and dCRT groups in patients with cT1b tumor.

This study has several other limitations. A nonrandomized and retrospective analysis was performed using the data from a single institution. Other studies comparing the ER-CRT and dCRT groups also mentioned the presence of selective bias; therefore, we attempted to reduce the effects of confounding factors by performing a multivariate analysis. Notably, we were able to reinforce the validity of the results of existing studies by confirming that ER was a predictor of local control even in the multivariate analysis.

\section{Conclusions}

This study confirmed that tumor length and ER were predictors of local recurrence after CRT in the multivariate analysis. ER was also useful as a salvage treatment for local recurrence, and can be expected to improve the organ preservation rate.

\section{Abbreviations}

5-FU: 5-Fluorouracil; AEs: Adverse events; CAT: Computerized axial tomography; CDDP: Cisplatin; Cl: Confidence interval; c/p: Clinical or pathological; CRT
: Chemoradiotherapy; CTV-P: Primary clinical target volume; dCRT: Definitive chemoradiotherapy; DSS: Disease-specific survival; EGD: Esophagogastroduodenoscopy; EMR: Endoscopic mucosal resection; ENI: Elective nodal irradiation; ER: Endoscopic resection; ESCC: Esophageal squamous cell carcinoma; ESD: Endoscopic submucosal dissection; EUS: Endoscopic ultrasound; GTV: Gross tumor volume; HR: Hazard ratio; IFI: Involved field irradiation; LRFS: Local recurrence-free survival; OS: Overall survival; RP: Radiation pneumonitis; RT: Radiotherapy; SM: Submucosal.

\section{Acknowledgements}

Not applicable.

\section{Authors' contributions}

TM and MM collected the data, performed the statistical analysis, and drafted the manuscript. HT and SO supervised especially for the endoscopic resection technique. $\mathrm{MH}$ and $\mathrm{HA}$ supervised the research. All authors read and approved the final manuscript.

\section{Funding}

Not applicable.

\section{Availability of data and materials}

The datasets used and/or analyzed during the current study are available from the corresponding author on reasonable request.

\section{Declarations}

\section{Ethics approval and consent to participate}

This study was approved by the institutional review board of Keiyukai Sapporo Hospital (permission code: 2021-8), and was conducted according to the principles of the Declaration of Helsinki.

\section{Consent for publication}

Not applicable.

\section{Competing interests}

The authors declare that they have no competing interests.

\section{Author details}

1'Department of Radiation Oncology, Keiyukai Sapporo Hospital, 1-1 Kita, Hondori-14, Shiroishi-ku, Sapporo 003-0027, Japan. ${ }^{2}$ Department of Surgery, Keiyukai Sapporo Hospital, Sapporo, Japan. ${ }^{3}$ Department of Radiation Oncology, Faculty of Medicine, Hokkaido University, North-15 West-7, Kita-ku, Sapporo 060-8638, Japan. ${ }^{4}$ Department of Gastroenterology, Keiyukai Daini Hospital, Hondori-13, Shiroishi-ku, Sapporo 003-0027, Japan.

Received: 21 July 2021 Accepted: 21 December 2021

Published online: 20 January 2022

\section{References}

1. Kitagawa $Y$, Uno T, Oyama T, et al. Esophageal cancer practice guidelines 2017 edited by the Japan Esophageal Society: part 1. Esophagus. 2019:16:1-24.

2. Ajani JA, D'Amico TA, Bentrem DJ, et al. Esophageal and esophagogastric junction cancers, version 2.2019, NCCN clinical practice guidelines in oncology. J Natl Compr Canc Netw. 2019;17(7):855-83.

3. Kato $H$, Sato A, Fukuda $H$, et al. A phase II trial of chemoradiotherapy for stage I esophageal squamous cell carcinoma: Japan Clinical Oncology Group Study (JCOG9708). Jpn J Clin Oncol. 2009:39(10):638-43.

4. Kato K, Igaki H, Ito Y, et al. Parallel-group controlled trial of esophagectomy versus chemoradiotherapy in patients with clinical stage I esophageal carcinoma (JCOG 0502). J Clin Oncol. 2019;37(4_suppl.7-7):1106-11. https://doi.org/10.1200/JCO.2019.37.4_suppl.7-7.

5. Yamada K, Murakami M, Okamoto Y, et al. Treatment results of chemoradiotherapy for clinical stage I (T1NOM0) esophageal carcinoma. Int J Radiat Oncol. 2006;64(4):1106-11. 
6. Kawaguchi Y, Nishiyama K, Miyagi K, et al. Patterns of failure associated with involved field radiotherapy in patients with clinical stage I thoracic esophageal cancer. Jpn J Clin Oncol. 2011;41(8):1007-12.

7. Ikeda A, Hoshi N, Yoshizaki T, et al. Endoscopic submucosal dissection (ESD) with additional therapy for superficial esophageal cancer with submucosal invasion. Intern Med. 2015;54(22):2803-13.

8. Murakami Y, Takahashi I, Nishibuchi I, et al. Long-term results of definitive concurrent chemoradiotherapy for patients with esophageal submucosal cancer (T1bN0M0). Int J Clin Oncol. 2015:20(5):897-904.

9. Nakatani $Y$, Kato $\mathrm{K}$, Shoji $\mathrm{H}$, et al. Comparison of involved field radiotherapy and elective nodal irradiation in combination with concurrent chemotherapy for T1bN0M0 esophageal cancer. Int J Clin Oncol. 2020;25(6):1098-104.

10. Yamamoto S, Ishihara R, Motoori M, et al. Comparison between definitive chemoradiotherapy and esophagectomy in patients with clinical stage I esophageal squamous cell carcinoma. Am J Gastroenterol. 2011;106(6):1048-54.

11. Motoori M, Yano M, Ishihara $\mathrm{R}$, et al. Comparison between radical esophagectomy and definitive chemoradiotherapy in patients with clinical T1bNOM0 esophageal cancer. Ann Surg Oncol. 2012:19(7):2135-41.

12. Japan Esophageal Society. Japanese Classification of Esophageal Cancer, 11th edition: part I. Esophagus. 2017;14(1):1-36.

13. Tanabe S, Myojin M, Shimizu S, et al. Dose-volume analysis for respiratory toxicity in intrathoracic esophageal cancer patients treated with definitive chemoradiotherapy using extended fields. J Radiat Res. 2013;54(6):1085-94.

14. Ishikawa $H$, Sakurai $H$, Tamaki Y, et al. Radiation therapy alone for stage I (UICC T1NOMO) squamous cell carcinoma of the esophagus: indications for surgery or combined chemoradiotherapy. J Gastroenterol Hepatol. 2006;21(8):1290-6.

15. Yoshimizu S, Yoshio T, Ishiyama A, et al. Long-term outcomes of combined endoscopic resection and chemoradiotherapy for esophageal squamous cell carcinoma with submucosal invasion. Dig Liver Dis. 2018;50(8):833-8.

16. Kawaguchi G, Sasamoto R, Abe E, et al. The effectiveness of endoscopic submucosal dissection followed by chemoradiotherapy for superficial esophageal cancer. Radiat Oncol. 2015;10:31

17. Hamada K, Ishihara R, Yamasaki Y, et al. Efficacy and safety of endoscopic resection followed by chemoradiotherapy for superficial esophageal squamous cell carcinoma: a retrospective study. Clin Transl Gastroenterol. 2017;8(8):e110.

18. Minashi K, Nihei K, Mizusawa J, et al. Efficacy of endoscopic resection and selective chemoradiotherapy for stage i esophageal squamous cell carcinoma. Gastroenterology. 2019;157(2):382-390.e3.

19. Hattori S, Muto M, Ohtsu A, et al. EMR as salvage treatment for patients with locoregional failure of definitive chemoradiotherapy for esophageal cancer. Gastrointest Endosc. 2003;58(1):65-70.

20. Yano T, Muto M, Hattori S, et al. Long-term results of salvage endoscopic mucosal resection in patients with local failure after definitive chemoradiotherapy for esophageal squamous cell carcinoma. Endoscopy. 2008;40(9):717-21.

21. Ego M, Abe S, Nakatani Y, et al. Long-term outcomes of patients with recurrent squamous cell carcinoma of the esophagus undergoing salvage endoscopic resection after definitive chemoradiotherapy. Surg Endosc. 2021;35(4):1766-76.

22. Al-Kaabi A, Schoon EJ, Deprez PH, et al. Salvage endoscopic resection after definitive chemoradiotherapy for esophageal cancer: a Western experience. Gastrointest Endosc. 2021;93(4):888-898.e1.

23. Uchinami $Y$, Myojin M, Takahashi $\mathrm{H}$, et al. Prognostic factors in clinical T1N0M0 thoracic esophageal squamous cell carcinoma invading the muscularis mucosa or submucosa. Radiat Oncol. 2016;11:84.

24. Thosani N, Singh H, Kapadia A, et al. Diagnostic accuracy of EUS in differentiating mucosal versus submucosal invasion of superficial esophageal cancers: a systematic review and meta-analysis. Gastrointest Endosc 2012;75(2):242-53.

25. Tsou YK, Lee CH, Le PH, et al. Adjuvant therapy for pT1a-m3/pT1b esophageal squamous cell carcinoma after endoscopic resection: esophagectomy or chemoradiotherapy? A critical review. Crit Rev Oncol Hematol. 2020;147:102883.

\section{Publisher's Note}

Springer Nature remains neutral with regard to jurisdictional claims in published maps and institutional affiliations.
Ready to submit your research? Choose BMC and benefit from:

- fast, convenient online submission

- thorough peer review by experienced researchers in your field

- rapid publication on acceptance

- support for research data, including large and complex data types

- gold Open Access which fosters wider collaboration and increased citations

- maximum visibility for your research: over $100 \mathrm{M}$ website views per year

At BMC, research is always in progress.

Learn more biomedcentral.com/submissions 